$\xi=-1$

\title{
Islanding detection for grid connected photo-voltaic systems for excess generation and under generation
}

\author{
Sunanda.E ${ }^{1 *}$, Divya spandana.S ${ }^{2}$, Ganapaneni Swapna ${ }^{3}$ \\ 1,2 UG Student, Department of Electrical Engineering, Koneru Lakshmaiah Education Foundation, Vaddeswaram, Guntur,A.P,India \\ ${ }^{3}$ Assistant professor, Department of Electrical Engineering,' Koneru Lakshmaiah Education Foundtion, Vaddeswaram,Guntur,A.P,India \\ *Corresponding author E-mail: sunanda.eluru97@gmail.com
}

\begin{abstract}
Islanding occurs mostly in wide areas. The Dc-link-voltage method gives the effective results when compared to the Under/over Frequency/Voltage method and Rate of Change of Frequency (ROCOF) method. This paper describes the islanding detection based on observation of the DC-Link-Voltage Source Converter (VSC) and also proposes a method for detecting islanding for Grid-connected PhotoVoltaic system based on rise or fall of DC-Link-Voltage for excess generation and under generation conditions. The proposed technique is validated through experimental results.
\end{abstract}

Keywords: Islanding; PV systems; Anti-islanding; Grid-Connected; DC-Link-Voltage.

\section{Introduction}

Nowadays Photo-Voltaic arrays are becoming more popular and the islanding detections are widely used. Islanding is the condition in which a Distributed-Generator (DG) should continue to power a location even though Electrical Grid Power is no longer present [1]. Islanding is a basic and dangerous condition, which may happen in a Power system. This condition is caused because of an inordinate utilization of Distributed-Generators in the Electrical Grid. This islanding can be intentional or unintentional. A planned island is called "intentional" and an unplanned island is called "unintentional" [2]. In intentional, the DistributedGenerator interface control is responsible of keeping up both the Voltage and Frequency on the islanded part of the system inside the admissible working limits. This unplanned islanding occurs when some part of the area in the Electric Power System is accidentally separated from the remaining area and the distributed energy resources continue to supply power. But islanding is hazardous for the operators because they don't know that the circuit is still supplying power and it may consist self-activation of devices. It also leads to damage customer equipment and DG's. Because of some of these reasons, DG must detect islanding and immediately stop feeding the circuit. This is known as antiislanding. So to decrease the cost of the Photo-Voltaic systems, the inverter must contain the anti-islanding procedures [1]. In order to avoid islanding suitable anti-islanding detection algorithm is included in the inverters and its corresponding changes for Gridconnected Photo-Voltaic systems. Islanding causes numerous issues, some of which are recorded underneath. They are Safetyconcern, Damage to the customer's equipments, inverter-damage. safety is the principle worry, as the Grid may still controlled in case of a power blackout because of power provided by dispersed generators, as clarified prior. This may confuse the Utility laborers and leads to danger for example, shock.
When the Distributed-Generator is connected with a power system, it becomes more complicated. The advantages of Small scale Distributed-Generators, be that as it may, compensate for the losses experienced by Utilities in different ways. For example, since conveyed age produces power where it's required; it diminishes the Electric load on transmission lines and decreases the requirement for expensive new transmission lines related with new power plants. Small scale Distributed-Generators likewise lessens costs for utilities during peak generation hours, i.e. daytime hours, especially in the mid year. This is especially applicable for photoVoltaic and other sunlight based controlled systems, which are most beneficial during peak utilization hours. As expanding quantities of Distributed-Generation systems are associated with Utility systems, Distribution engineers are ending up progressively keen on assessing the danger of accidental islanding. The operation of Distributed-Generator consists of 2 cases: Distributed-Generator under islanding condition and Distributed-Generator under nonislanding condition [10]. Enormous increment being used of Distributed-Generator sources at distribution site requires specialists to discover answer for islanding phenomenon [18]. Islanding detection schemes are classified based on Communication-Based Detection Scheme for Synchronous Distributed-Generators and Local Detection schemes for Inverter Distributed-Generator.

Mainly, Islanding detection methods are of two types. They are Active and passive [3]. In Active method, an additional signal is injected into the line and observes the effects which are intentionally created on the grid [4].Active methods are mostly based on the changes in the voltage, frequency, impedance parameters. The two techniques in the Active detection method are Slip Mode Frequency Shift (SMS) and Active Frequency Drift (AFD), which is based on the analysis of the changes on the grid [4]. The active method considers the feedback control mechanism that detects the changes in Frequency $(\mathrm{F})$ or $\operatorname{Voltage}(\mathrm{V})$ at PCC [5]. Active 
islanding detection method has the advantage of decreasing the Non-Detection-Zone (NDZ). In Active Schemes, unwanted signals are infused locally into the system and the reactions of these unwanted signals are utilized to detect islanding conditions. Active Schemes incorporate Impedance values, Voltage Phase Jump,Voltage Shift, Phase Shift, Frequency Shift and Hormonic Distortions [19]. These active methods are easy to implement and develop analytically. But due to some of the power quality issues active method is not considered.

This paper presents islanding detection techniques using passive method. Generally, passive method refers to the variations in transient changes on the grid such as voltage, current, frequency. These are classified as Under/over Frequency/Voltage method, ROCOF method, and DC Link Voltage method [6]. In this technique changing in the parameter values are considered when the grid is islanded. So by setting a proper threshold value can help to differentiate between the islanding and Grid-connected conditions [7]. In general, passive methods have extraordinary trouble taking out all NDZ's that it is hard to discover threshold limits. The conduct and execution of passive techniques is hard to anticipate when different inverters are available in the potential island.

In Under/Over Voltage method, voltage (V) is the main parameter. The change in the voltage gives the results in detecting the islanding condition [9]. If there is a rise in voltage value than the preset threshold value, then the islanding command is triggered. This is known as Over Voltage islanding detection method. If there is a fall in voltage value than the preset threshold value, then the islanding command is triggered. Under/Over Frequency is similar to that of Under/Over Voltage method. But here the parameter observed is Frequency.

In ROCOF method, the change in frequency occurred due to the imbalance between the Mechanical input Power and the load [11]. When the frequency exceeds its threshold value, a relay gets triggered and shows islanding detection command [12]. This method was used widely when compared to the others. Comparison of ROCOF expects that loss of mains will cause a sudden change in Frequency [17]. However, Comparison of ROCOF separates between changes in Frequency because of loss of mains, and changes because of far reaching system unsettling influences by utilizing is blocking signal

In DC-Link-Voltage method, the dc-link-voltage value is compared with the dc-link threshold value. The relay gets activated when the dc-link threshold value is exceeded [1].By increasing the threshold value, the detection time of dc-link-voltage relay is increased. As DC-Link-Voltage method gives the efficient results, this paper represents islanding detection in DC-Link-Voltage method [1]. The presented Anti-islanding Technique is based on the observation of the dc-link-voltage, which rises significantly during transient Grid-faults [8]. The variations in the detection can be noticed in the VSC of the Photo-Voltaic inverters that controls the dc-link-voltage.

In any case, the over/under Voltage and Frequency techniques won't work appropriately to identify the island when the neighborhood loads are firmly coordinating the Distributed-Generator yield control. For this situation the Voltage and Frequency move are lacking to surpass the voltage and recurrence breaking points to permit the over/under Voltage or Frequency protection trip [16]. Since the Distributed-Generator as of now observed the terminal voltage for its own particular control reason, including latent islanding recognition normally requires minimal extra equipment also, can be actualized requiring little to no effort

The paper consists of following structure. Section 1 shows the General description of Islanding of Photo-Voltaic system. Section 2 presents the considered grid-connected Photo-Voltaic system topology. Section 3 presents the proposed technique (ROFVDC) of Islanding detection. Section 4 presents the experimental results.

\section{Grid-connected pv system topology}

Fig 2.1 represents the general Block Diagram of Grid-connected Photo-Voltaic system. The input Voltage (V) from the PhotoVoltaic system was sent to Buck or Boost converter to increase or decrease the voltages as per the requirements and then sends to DC load. The power from the PV was given to an inverter through the bus terminal. This inverter converts the DC supply to AC supply that was given to the grid and the inverter also gives the power to the AC load.

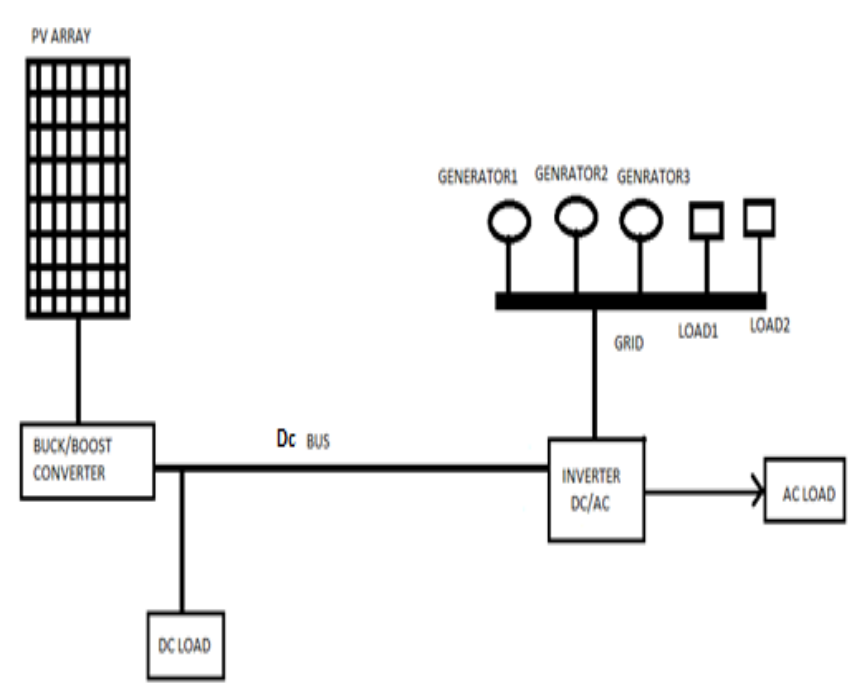

Fig 2.1: Block Diagram of Grid-connected Photo-Voltaic system

The Photo-Voltaic system was connected to a grid through an inverter because the power delivered by the Photo-Voltaic system was only dc. So we use an inverter to convert dc power to ac power because the utility gird supplies/consumes the ac power. The components that are used in this system are PV array, boost converter, inverter, and utility grid. Photo-Voltaic cells are figured into different shapes and sizes. These can be circles, rectangles and squares [13]. The size, shape and number of the Photo-voltaic cell for each Photo-voltaic module can be decided by the material by which the Photo-Voltaic cell is made.

PV arrays are designed for generating electricity. It converts direct sunlight into electricity. These PV arrays are formed by many components, including solar panels. The prices of PV arrays are rapidly decreased in recent years due to the high growth of photovoltaic. Nowadays grid-connected PV arrays without a battery setup are very simple. Contingent upon development, photovoltaic modules can deliver power from a scope of frequencies of light, however more often than not can't cover the whole sun powered range (particularly, bright, infrared and low or diffused light). Subsequently, a great part of the occurrence daylight vitality is wasted by Photo-Voltaic modules, and they can give far higher efficiencies if lit up with monochromatic light. Subsequently, another plan idea is to part the light into six to eight diverse wavelength extends that will create an alternate shade of light, and direct the bars onto distinctive cells tuned to those ranges. This has been anticipated to be fit for raising productivity by half $(50 \%)$. Small scale inverted Photo-Voltaic panels are wired in parallel, which delivers more yield than ordinary boards which are wired in 
arrangement with the yield of the arrangement dictated by the most minimal performing board. Small scale Inverters work autonomously so each board contributes its greatest Maximum output given the accessible daylight.

Maximum-Power-Point-Tracking (MPPT or PPT) is a method utilized ordinarily with wind turbines and Photo-Voltaic to maximize control extraction under all conditions. MPPT can be classified as Perturb \& Observe, Constant Voltage, and Incremental Conductance. The MPP power is defined as the product of MPP Voltage and MPP current. Sun powered inverters utilize Maximum-Power-Point-Tracking (MPPT) toward to get the most extreme conceivable power from the Photo-Voltaic array. Sun oriented cells have a connection between sun based light, temperature and aggregate protection that creates a non-direct yield effectiveness known as the I-V Curve. It is the motivation behind the MPPT framework to test the yield of the cells and decide a protection (stack) to acquire most extreme power for any given natural conditions [14].

Boost Converter is a dc to dc Power Converter which step up's the output Voltage from its input. Boost Converter is similar to that of Buck Convert but there is a difference in their operation. Inductor, Diode, Switch, Capacitor, Amplifier are the main components present in the Boost Converter. Its operation depends on by varying the time. The dc input Voltage from the Photo-Voltaic array was given to the Boost Converter to step-up the Voltage and then sent to an inverter.

Generally, renewable energies are used as DistributedGenerators. Here, solar energy is used as a Distributed-Generator. When islanding condition takes place in the Power system to avoid islanding condition these Distributed-Generators will supply the power, in order to avoid the damage of the equipment and other consequences. The systems which are used to store this energy are called Distributed Energy Storage Systems.

Inverter plays a very important role in Grid-connected systems. It converts the dc supply from Photo-Voltaic array into ac supply and supplies to the grid. To detect the islanding conditions these inverters should include the best detection algorithms. Inverters are used in many applications depending upon their range. There are 3 types of inverters based on their output characteristic. They are sine wave, square wave, and pure sine wave inverter. Grid tie inverters, otherwise called or Synchronous inverters, synchronize the stage and Frequency of the Current to fit the utility Grid. The yield voltage is additionally balanced marginally higher than the Grid Voltage all together for overabundance Power to stream outwards to the network. Some of the advantages of Grid tie inverters are: (a) it saves huge amounts of money with solarpanels, installation costs etc., by giving high efficiency (b) The Electric Power Grid is from multiple points of view additionally a battery, without the requirement for support or substitutions, and with much better productivity rates. As it has greater power goes to waste with regular battery systems.

Bi-directional inverters are utilized to offer surplus power created by sun oriented power framework back to the service organization by utilizing Photo-Voltaic array attach purposes to sustain the overabundance vitality back onto the network. The $\mathrm{Bi}$ Directional Inverter will dependably be introduced in the meantime as your sunlight based boards or wind turbines. This system likewise holds an additional motivating force for home and entrepreneurs by giving an extra power source which goes about as a reinforcement when the Utility Company is down and neglects to give you power to your mains. The role of multi-level inverter can definitely influence the adequacy of some islanding discovery strategies [15].
Utility grid is a network that delivers Electric Power from producers to consumers. If the Power from PV array is excess then the utility grid consumes the power and if the power from PV array is low then the utility grid feeds the PV array. There is also a ac load is connected near the grid to increase or decrease the load at the grid side.

The Electric Grid is classified as regional-grid and nationalgrid. In regional-grid, the transmission lines in a particular area are interconnected to various transmission systems. But the formation of regional grid leads to the national-grid. The interconnection of the Grid gives the best utilization of energy asset and guarantees incredible security to supply. It makes the framework conservative and dependable.

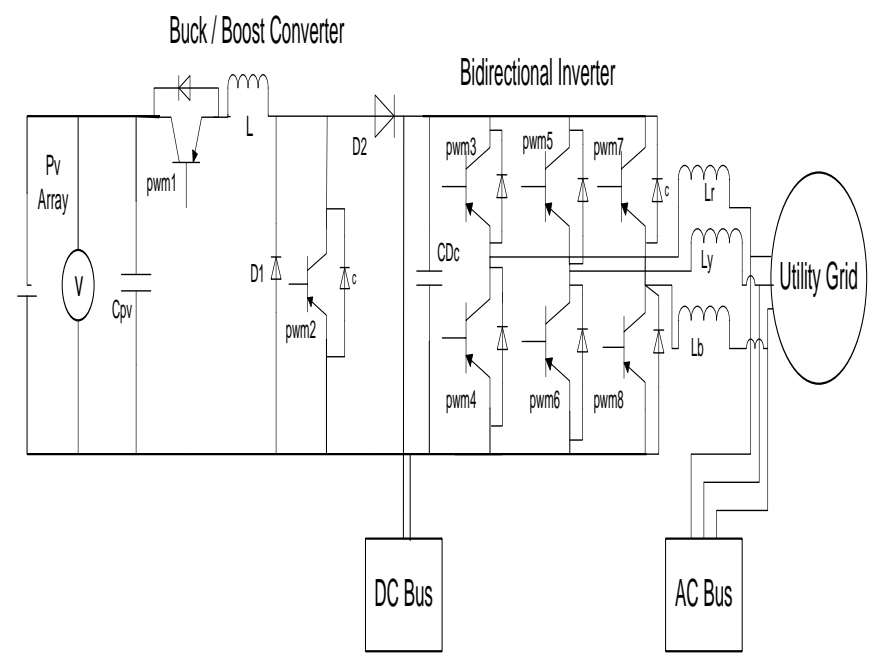

Fig 2.2: Detailed diagram of grid-connected PV systems

The above Fig 2.2 shows the Grid-Connected Photo-Voltaic system consists of $n$ number of panels. If the input Voltage from the Photo-Voltaic array is low, it gives the supply to the DC load as well as AC load and the grid feeds the PV as it is having low supply. When the input voltage from the PV array is excess, it supplies to the DC load, AC load and also to the grid.

In the paper [1], the islanding detection was done based on the local loads and local generators during a particular time like peak time and off-peak times. From the base paper [1], it is proved that DC-Link-Voltage method detects the islanding condition within short period of time. The effect on dc-link-voltage depends on the type of loads. It is observed that the dc-link-voltage increases as the Connected Loads increased during islanding.

If the Frequency is decreased in the respective islanding detection method, that leads to the change in the ROCOF. So, whenever the ROCOF threshold value exceeds its value, the relay gets activated [20]. The Frequency relays has some grid codes which take more time to detect the islanding condition. Therefore, it is observed that DC-Link-Voltage method gives the best detecting time in all cases.

In present paper, the islanding detection was identified according to the generation of power in the Photo-Voltaic system. This paper consists of 2 cases i.e., Under Generation and Excess Generation. The below section tells what happens during these cases, how the islanding condition is determined and how much time it takes to detect the islanding condition.

\section{Rise or Fall of DC-Link-Voltage (ROFVDC)}

The proposed methodology of islanding detection is robust and is expanded for two cases as follows. 


\section{CASE (i): Under Generation}

When the PV generation is not sufficient to meet the local loads, the utility grid feeds the remaining load demand. This condition can be identified by nearly $0^{\circ}$ shift in the phase voltage and current at PCC. During this condition, if PV system is isolated from the grid, a fall in dc voltage is observed and when the preset difference in fall of dc voltage is observed, again an islanding detection command is triggered. Mostly, the islanding condition can be detected within $0.25 \mathrm{sec}$.

\section{CASE (ii): Excess Generation}

Under excess generation of electric power after meeting the dc and ac local loads is exported to the utility grid. This condition can be identified by nearly $180^{\circ}$ phase shift in the current and phase voltage at the PCC to the Grid. During this condition, if PV system is isolated from the grid a rise in DC Link Voltage is observed and when a preset difference in rise of dc voltage is observed, an islanding detection command is triggered. Mostly, the islanding condition can be detected within $0.25 \mathrm{sec}$

The Block Diagram of the proposed control technique is shown below.

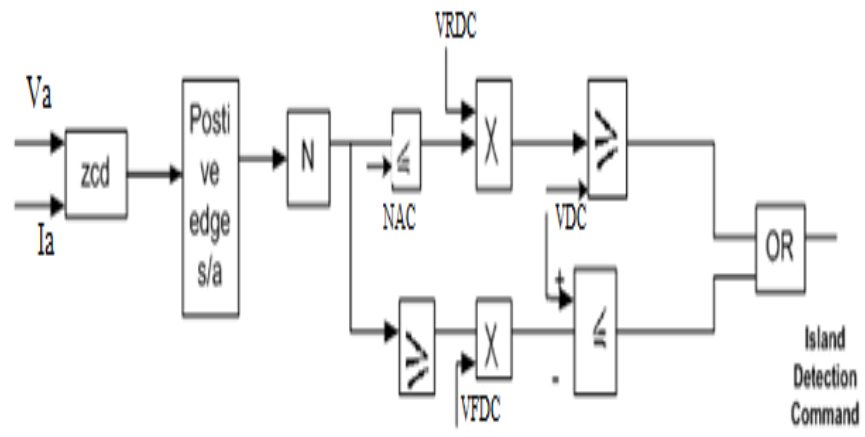

Fig 3.1: Controlled Block Diagram of Islanding Detection

Where,

Va- Grid phase voltage.

Ia- Phase current at PCC

$\mathrm{N}$-sample difference between positive edge of Va \&Ia

NAC- No. of samples for quarter cycle of zcd output.

NHC - No. of samples of half cycle of zcd output

VRDC - preset raise of dc voltage.

VFDC - Preset fall of dc voltage.

zcd - zero cross detection.

Fig 3.1 represents the controlled block diagram of islanding detection. When voltage and current passes through the zero cross detection, the positive edge of samples between the voltage and current are observed. The preset raise of dc voltage is combined with NAC, if this value is greater than dc voltage then islanding detection command shows 1 . If that value is less than dc voltage then islanding detection command shows 0 .

\section{Experimental results}

This section represents the experimental results of islanding detection and parameter values for two cases i.e.,(i) Under Generation, (ii)Excess Generation.
Table 4.1: The values of the parameters used in the Block Diagram

\begin{tabular}{|l|l|l|}
\hline S.No. & PARAMTERS & VALUES \\
\hline 1 & PV array & $300 \mathrm{~V}, 8 \mathrm{~A}$ \\
\hline 2 & DC-Link capacitance, Cdc & $450 \mathrm{~V}, 2200 \mathrm{uF}$ \\
\hline 3 & $\begin{array}{l}\text { dc-dc converter input capacitance, } \\
\text { Cpv }\end{array}$ & $450 \mathrm{~V}, 1100 \mathrm{uF}$ \\
\hline 4 & dc-dc converter inductor, $\mathrm{L}$ & $5 \mathrm{mH}$ \\
\hline 5 & $\begin{array}{l}\text { dc-dc converter switches, } \\
\text { pmw1,pmw2 }\end{array}$ & IGBT-1200V,50A \\
\hline 6 & $\begin{array}{l}\text { DC critical load } \\
\text { Bi-directional converter switches } \\
\text { pwm-3- pwm-8 }\end{array}$ & $\begin{array}{l}\text { Resistive Load- } \\
\text { I00V }, 800 \mathrm{~W}\end{array}$ \\
\hline 7 & $\begin{array}{l}\text { AC critical load } \\
8\end{array}$ & $\begin{array}{l}3 \text {-induction motr load } 0.5 \\
\mathrm{HP}, 312 \mathrm{~V}\end{array}$ \\
\hline 9 & Filter inductors $\mathrm{L}_{\mathrm{r}}, \mathrm{L}_{\mathrm{y}}, \mathrm{L}_{\mathrm{b}}$ & $12 \mathrm{mH}$ \\
\hline
\end{tabular}

(i)

Under generation:

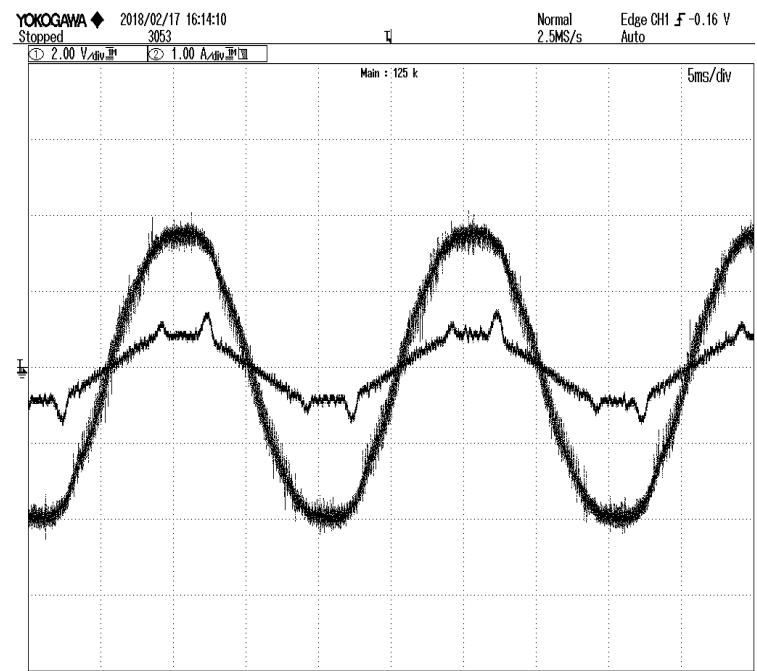

Fig 4.1: The waveform of current and voltage for under generation

Case

The above Fig 4.1 and Fig 4.2 describes about the under generation of the utility grid.

The Fig 4.1 shows that a phase voltage and phase current at the PCC of grid are in-phase. Therefore the power supplied from the grid in the case of under generation.During this condition the voltage level decreases due to the grid loss. Fig 4.2 shows dc voltage transients during grid loss. A fall in dc voltage immediately after grid loss is observed. When it falls below the preset value islanding is detected after $0.25 \mathrm{sec}$. So, here the Fall of DC-Link-Voltage method takes place.

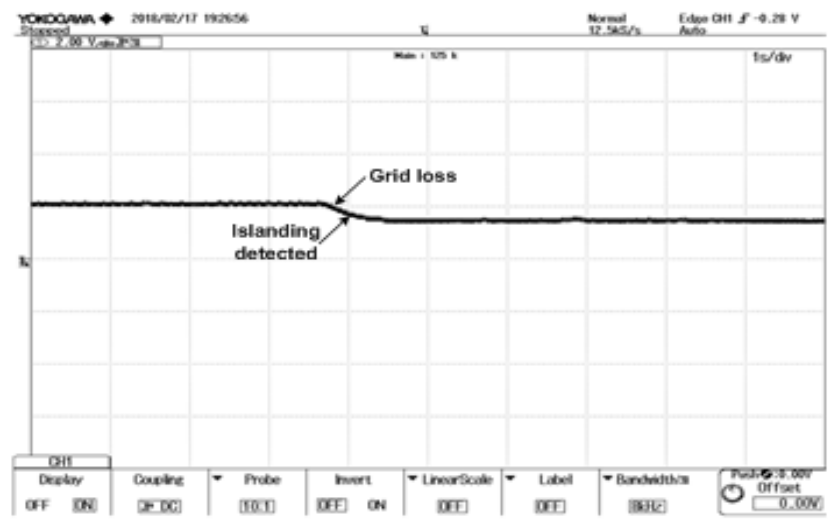

Fig 4.2: Voltage waveform for under generation case when there is a grid loss 
(ii) Excess generation:

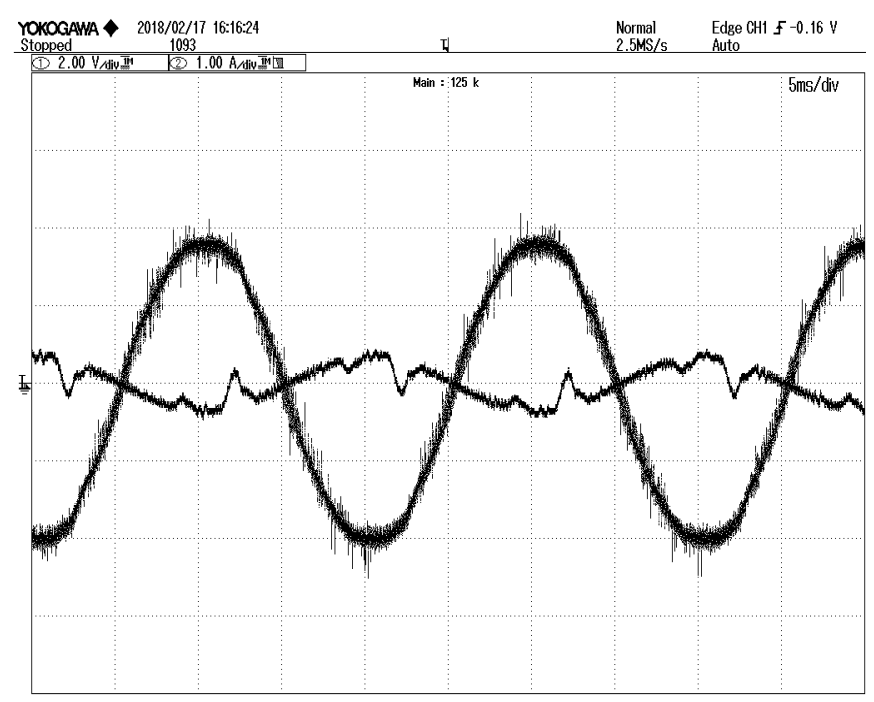

Fig 4.3: The waveform of current and voltage for Excess Generation

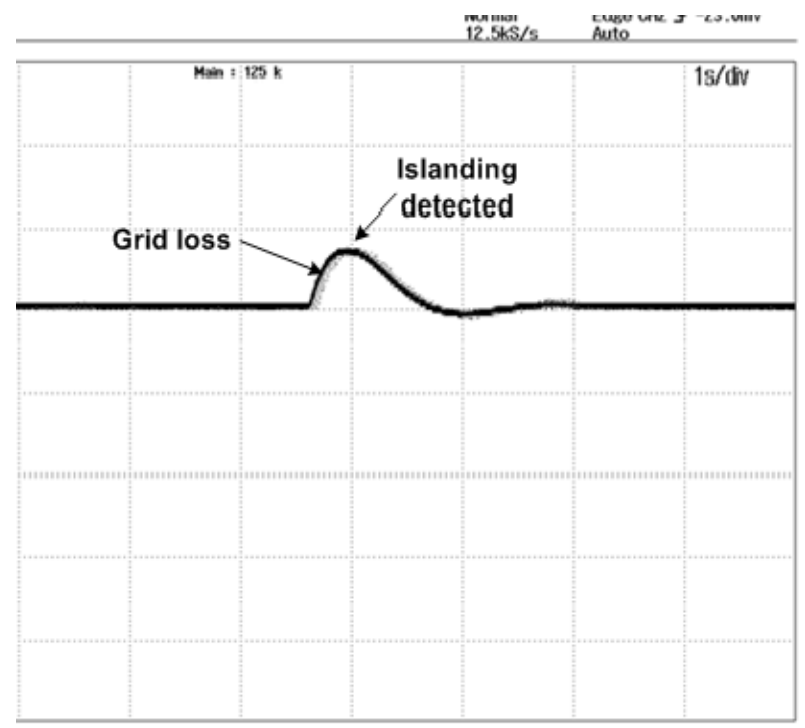

Fig 4.4: Voltage waveform for Excess generation case when there is a grid loss

The figures 4.3 and 4.4 describes about the excess generation. Fig 4.3 shows the phase of current and phase voltage at the PCC to the grid which are out of phase. Therefore, the power is supplied to the grid and voltage value is increased.

The graph from the Fig 4.4 shows that PV system is isolated from the grid. A raise in dc voltage immediately after grid loss is observed. When it rises above the preset value islanding is detected after $0.25 \mathrm{sec}$. So, here the Rise of DC-Link-Voltage method takes place.

\section{Conclusion}

Experimental results show that the dc-link-voltage is the best method to detect islanding condition within less time. This DCLink-Voltage would rise for the case of islanding under excess generation mode and would fall for the case of under generation. The proposed methodology for islanding detection proved satisfactory under all operating conditions with a good reaction time of 0.25 seconds. Thus it can be concluded that this is a novel and efficient solution for islanding detection under all operating condition of the grid tied PV system.

\section{References}

[1] V. Banu and M. Istrate, "Islanding prevention scheme for GridConnected Photovoltaic systems in Matlab/Simulink," 2014 49th International Universities Power Engineering Conference (UPEC).

[2] IEEE Standard for Interconnecting Distributed Recourses With Electrical Power Systems, no. 1547 IEEE, 2003.

[3] Toma'sSko cil, OriolGomis-Bellmunt, Daniel MontesinosMiracle, "Passive and Active Methods of Islanding for PV systems"

[4] Mohammed Laour, AchourMahrane, FethiAkel, and DouadiBendib, "Implementation of Active Anti-Islanding Methods Protection Devices for Grid-Connected Photovoltaic Systems".

[5] Wei Yee Teoh, Chee Wei Tan, “An Overview of Islanding Detection Methods in Photovoltaic Systems", International Science Index, Vol:5, No:10, 2011 waset.org/Publication/5748.

[6] Zhu, Y., Shi, X.: 'Analysis of the influence of load to islanding passive detection method'. The Second IEEE Int. Conf. on Information Management and Engineering (ICIME), Chengdu, People's Republic of China, April 2010, pp. 333-336

[7] Hesanvaheid, Reza Noroozain, AbolfazlJalilvand, Gevorg B.Gharehpetian, “A New Method For Islanding Detection Of Inverter Based Distributed Generation Using DC Link Voltage Method", IEEE Transactions On Power Delivery Vol.26, No.2, April 2011.

[8] Ioan Viorel Banu, Marcel Istrate, Dragos Machidon, RazvanPantelimon Gheorghe Asach, "A Study on Anti-Islanding Detection Algorithms for Grid-Tied Photovoltaic Systems"

[9] Anila Antony, Devika Menon ,"Islanding Detection Technique of Distribution Generation System". International Conference on Circuit, Power and Computing Technologies [ICCPCT],2016.

[10] F. S. Pai and S. J. Huang, "A detection algorithm for islanding prevention of dispersed consumer owned storage and generating units," IEEE Trans. Energy Convers., vol. 16, no. 4, pp. 346-351, Dec. 2001

[11] Rafał Bugdał, Adam Dyśko, G.M. Burt, J.R. McDonald, "Performance analysis of the ROCOF and Vector Shift methods using a dynamic protection modelling approach", Effect of distributed generation on power system protection, PSP 2006.

[12] P.J. O'Kane, B. Fox, "Loss of Mains Detection for Embedded Generation by System Impedance Monitoring”, in Proc. 1997 International Conference on Developments in Power System Protection, pp. 95-98.

[13] Prakash Kumar Dewangan, "Control and Design of an Inverter for Grid Connected Photo Voltaic (PV) Generation and research Oppurtunities", International Journal of Engineering Research \&Technology (IJERT).

[14] K.Manohar, ,P.Sobha Rani, "Mppt and Simulation for a GridConnected Photovoltaic System and Fault Analysis", The International Journal of Engineering And Science (IJES) .

[15] R. Bhandari, M. Ropp, and S. Gonzalez, Investigation of two anti-islanding methods in the multi-inverter case, Proceedings of the IEEE Power Engineering Society 2008 Summer Meeting, July 2008,6 pp.

[16] A. S. Aljankawey, Walid G. Morsi, L. Chang, and C. P. Diduch, "Passive Method-Based Islanding Detection of RenewableBased Distributed Generation: The Issues", Electric Power and Energy Conference (EPEC), 2010 IEEE.

[17] C. G. Bright, "COROCOF: comparison of rate of change of frequency protection. A solution to the detection of loss of mains", in Proc. of the Seventh IEEE International Conference on Developments in power system protection. pp. 70-73, 2001.

[18] Rohit S. Kunte, Wenzhong Gao, "Comparison and review of islanding detection techniques for distributed energy resources", Power Symposium, 2008. NAPS '08. 40th North American.

[19] Bo-tao li, Peng li, Ling zhang, Meng-chao ma, "Research on Islanding Detection Method for PV Power System Based on Chaos Theory", Electricity Distribution, 2008. CICED 2008. China International Conference

[20] Liu Zhifeng, Chen Yuchen, Zhang Liping, Jia Chunying, "Research on Islanding Detection of Grid-Connected System", (IJACSA) International Journal of Advanced Computer Science and Applications, Vol. 6, No. 7, 2015. 